\title{
Reassessing advance care planning in the light of covid-19
}

\author{
Focus on creating a shared narrative not recording choices
}

\begin{abstract}
Sarah A Hopkins geriatric medicine registrar, Roberta Lovick patient and carer representative, Louisa Polak visiting researcher, Ben Bowers doctoral student, Tessa Morgan doctoral student, Michael P Kelly senior visiting fellow, Stephen Barclay academic general practitioner
\end{abstract}

Primary Care Unit, Department of Public Health and Primary Care, University of Cambridge, Cambridge, UK

Compared with younger people, older people and those with frailty are more likely to die from acute infections, such as covid-19, and less likely to survive intensive care. ${ }^{12}$ This has prompted calls internationally for advance care planning in these vulnerable populations, focusing on documenting individuals' preferences for resuscitation and hospital admission. ${ }^{34} \mathrm{We}$ suggest that the benefits of advance care planning derive more from its process than from the plans it produces, and that recognising this is essential for provision of optimum care for patients and their families. Moreover, an overemphasis on achieving individual choice, the stated purpose of advance care plans, may paradoxically undermine good care. ${ }^{5}$

\section{Process versus product}

Covid-19 guidance on advance care planning has largely focused on its product: a plan recording an individual's treatment preferences. ${ }^{34}$ Yet evidence suggests that some of the main benefits that frail patients and their loved ones experience from advance care planning are strengthened relationships with each other and their clinical teams, and support through the experiences of living and dying with frailty and bereavement..$^{6-9}$ These benefits come largely from the conversations that constitute the planning process, particularly when these occur over time and include the patient's family and loved ones.

Such conversations help to shape a jointly constructed life story that gives meaning and context to decisions and informs ongoing person centred care. ${ }^{10}$ The importance of this approach to older people is shown by their high prioritisation of not being a burden to family, a goal that the process of advance care planning can help to achieve. ${ }^{11}$ Thus individuals do not act alone; rather, they consider the priorities and concerns of those around them. ${ }^{51012}$ This is reflected in a relational model of autonomy: decisions are situated within social contexts, and social relationships enhance autonomy. ${ }^{10}$

If we do not adequately appreciate the inherent value of compassionate, collaborative conversations with patients and their families, we risk reducing advance care planning to a tickbox exercise focused on a predetermined list of preferences, including place of care, level of treatment, and resuscitation status. ${ }^{7}$ This reductive "choosing" exercise prioritises clinically directed issues, paradoxically undermining autonomy by sidelining other factors that may be more important to the person and those around them. ${ }^{12}$ It also misses opportunities to create shared meaning and strengthen relationships, both essential ingredients of person centred care.

The consequences of focusing on the plan rather than the process have already been witnessed in the UK pandemic. Some care home residents have been sent standardised letters asking them to specify their treatment preferences without having had individual conversations with their clinicians. ${ }^{13}$ This has caused understandable confusion and distress, raising concerns about denial of treatment. ${ }^{13}$ Rather than contributing to these concerns, good advance care planning should help to alleviate them.

How, then, should we approach advance care planning during the pandemic? Research has investigated the experiences and priorities of frail and older people in planning their care. . $^{7.9} 1114$ However, few attempts have been made to collaborate with patients and their loved ones to design approaches to meet their needs. ${ }^{89}$ Thus translating evidence about patients' priorities into best practice remains largely a matter of clinical expertise. Many frail people prioritise living day to day over future planning, and conversations might first need to explore how to adjust to the new circumstances of living with frailty during the pandemic, before they feel able to look to the future. ${ }^{814}$

We suggest that advance care planning should focus on encouraging people to voice their concerns and priorities, providing the information they want, and facilitating conversations between loved ones at this emotionally and logistically difficult time. For some, such conversations might sensitively enable an understanding of the possibility of dying in the near future and help to identify goals and priorities for treatment and care. This might result in people declining certain treatments or being gently told that some treatments would be medically inappropriate. 


\section{New challenges, new opportunities}

While social distancing and remote consultations make advance care planning especially challenging, there are also potential opportunities. Rates of advance care planning with frail patients are low; having a "trigger" to initiate conversations is a key facilitator. ${ }^{8}$ Some may find the universal threat of covid-19 a more acceptable reason to discuss future care than a diagnosis of frailty, a label many find pejorative. ${ }^{15}$

Heightened public and professional interest provides an opportunity to establish a more nuanced, relational approach to choice, founded on co-creating shared narratives. ${ }^{10}$ This reflects existing best practice which recognises that advance care planning is an important facilitator of meaningful conversations, providing support through the experiences of living and dying with frailty. During and after the pandemic, policy and practice should focus less on advance care plans and more on the planning process.

We thank Andrée le May and John Gabbay for their help with refining and developing these ideas.

Competing interests: The BMJ has judged that there are no disqualifying financial ties to commercial companies. SAH is supported by the Addenbrooke's Charitable Trust and the Evelyn Trust. BB is funded by the National Institute for Health Research (NIHR) School for Primary Care Research. SB is supported by the NIHR Applied Research Collaboration East of England. The views expressed are those of the authors and not necessarily those of the NHS, the NIHR, or the Department of Health and Social Care.

Provenance and peer review: Not commissioned; externally peer reviewed.

1 Chen $\mathrm{T}, \mathrm{Wu} \mathrm{D}, \mathrm{Chen} \mathrm{H}$, etal . Clinical characteristics of 113 deceased patients with coronavirus disease 2019: retrospective study. BMJ 2020;368:m1091. 10.1136/bmj.m1091 32217556
2 Muscedere J, Waters B, Varambally A, etal . The impact of frailty on intensive care unit outcomes: a systematic review and meta-analysis. Intensive Care Med 2017:43:1105-22. 10.1007/s00134-017-4867-0 28676896

3 NHS England, NHS Improvement. Novel coronavirus (COVID-19) standard operating procedure: Community health services. 2020. https://www.england.nhs.uk/coronavirus/ wp-content/uploads/sites/52/2020/04/C0198-community-health-services-sop.pdf

$4 \quad$ National Hospice and Palliative Care Organisation. Coronavirus disease 2019 (COVID-19) shared decision-making tool. 19 March 2020. https://www.nhpco.org/wp-content/uploads/ COVID-19-Shared-Decision-Making-Tool.pdf

$5 \mathrm{Mol}$ A. The logic of care: health and the problem of patient choice. Routledge, 2008 $10.4324 / 9780203927076$.

6 Martin DK, Emanuel LL, Singer PA. Planning for the end of life. Lancet 2000;356:1672-6. 10.1016/S0140-6736(00)03168-8 11089839

7 Pollock K, Wilson E. Care and communication between health professionals and patients affected by severe or chronic illness in community care settings: a qualitative study of care at the end of life. NIHR Journals Library, 2015.

8 Combes S, Nicholson CJ, Gillett K, Norton C. Implementing advance care planning with community-dwelling frail elders requires a system-wide approach: An integrative review applying a behaviour change model. Palliat Med 2019;33:743-56. 10.1177/0269216319845804 31057042

9 Hopkins SA, Bentley A, Phillips V, Barclay S. Advance care plans and hospitalized frail older adults: a systematic review. BMJ Support Palliat Care 2020;bmjspcare-2019-002093. 10.1136/bmjspcare-2019-002093 32241957

10 Gómez-Vírseda C, de Maeseneer Y, Gastmans C. Relational autonomy: what does it mean and how is it used in end-of-life care? A systematic review of argument-based ethics literature. BMC Med Ethics 2019;20:76. 10.1186/s12910-019-0417-3 31655573

11 Etkind SN, Bone AE, Lovell N, Higginson IJ, Murtagh FEM. Influences on care preferences of older people with advanced illness: a systematic review and thematic synthesis. J Am Geriatr Soc 2018;66:1031-9. 10.1111/jgs.15272 29512147

12 Borgstrom E, Walter T. Choice and compassion at the end of life: A critical analysis of recent English policy discourse. Soc Sci Med 2015;136-137:99-105. 10.1016/j.socscimed.2015.05.013 25989003

13 Care home residents claim they are being asked to sign letters agreeing they won't go to hospital if they get coronavirus. Daily Mail $2020 \mathrm{Apr} 16$. https://www.dailymail.co.uk/news article-8226675/Care-home-residents-asked-sign-letters-agreeing-WONT-hospital-COVID19.html

14 Etkind SN, Lovell N, Nicholson CJ, Higginson IJ, Murtagh FE. Finding a 'new normal' following acute illness: A qualitative study of influences on frail older people's care preferences. Palliat Med 2019:33:301-11. 10.1177/0269216318817706 30526371

15 Nicholson C, Gordon AL, Tinker A. Changing the way "we" view and talk about frailty.... Age Ageing 2017;46:349-51. 10.1093/ageing/afw224 27932367

Published by the BMJ Publishing Group Limited. For permission to use (where not already granted under a licence) please go to http://group.bmj.com/group/rights-licensing/ permissions 